\title{
Prospective study of timing of elective caesarean section at different gestational ages to assess neonatal outcome in tertiary hospital, New Delhi
}

\author{
Godishela Rammurthy ${ }^{1}$, Seema Pundir ${ }^{2, *}$, Neeraj Sharma ${ }^{3}$, Sanjay Choudhary ${ }^{4}$, Ritu Khatuja ${ }^{5}$ \\ ${ }^{1}$ Senior Resident, ${ }^{2}$ Specialist, ${ }^{3,4}$ Senior Specialist, ${ }^{5}$ Assistant Professor, Dept. of Obstetrics and Gynaecology, Dr. Baba Saheb \\ Ambedkar Medical College \& Hospital, Rohini Delhi, India \\ *Corresponding Author: \\ Email: seemapundir2014@gmail.com
}

\begin{abstract}
Timing of elective caesarean deliveries at term has become an important issue nowadays due to the progressive increase in caesarean delivery rates in recent years all over the world. Advanced maternal age at conception, legal considerations, assisted reproductive techniques and maternal request play an important role in the increased rates of elective repeated caesarean delivery. However the most important cause is the increased number of cases with repeated caesarean sections. Hence, study was undertaken with the aim to find correlation between gestational age of elective caesarean section performed at 38 weeks, 39 weeks, 40 weeks and neonatal outcome. A prospective comparative study consisting of 750 patients was done over a period of one and half year in Department of Obstetrics and Gynaecology Dr. Baba Saheb Ambedkar Hospital in Delhi. Neonatal outcomes were based on: Birth weight, apgar score (at 1 and 5 minutes), Respiratory complications, Hypothermia (axillary temperature $<36.50 \mathrm{C}$ within 1 hour of life), Hypoglycaemia (< $40 \mathrm{mg} / \mathrm{dl}$ within 1 hour of life), feeding difficulties. In our study neonatal outcomes are similar in elective caesarean sections done at 38, 39 and 40 weeks of gestation. So elective caesarean section can be done in between 38 to 40 weeks depending upon the resources available in a as the neonatal outcomes at 38 weeks are similar to 39 and 40 weeks. But further trials with larger sample size are needed to validate the results.
\end{abstract}

Keywords: Elective caesarean section, neonatal outcome, Gestational age, Apgar score, Respiratory complications.

\section{Introduction}

Pregnancy and parturition are events of considerable importance in the life cycle of women. Pregnant women may deliver their children via normal vaginal delivery or through caesarean section. Of all deliveries, however, approximately $10 \%$ are considered high-risk, some of which require caesarean section. ${ }^{1}$

Caesarean section (CS) is defined as "the delivery of a fetus through an abdominal incision (laparotomy) followed by incision of the uterine wall (hysterotomy). ${ }^{2}$

Caesarean section is divided into two sub-types as far as urgency of operation is concerned, Emergency caesarean section (ECS), elective caesarean section. ${ }^{3}$ World Health Statistics reveal a global CSR of $16 \%$, exceeds the recommended upper limit of $15 \%$. The increased rate of caesarean section can be explained by both medical and non-medical factors. Among the medical factors are increase in maternal age and body mass index, as well as changes in obstetric practice and technology. Some non-medical factors are caesarean section requested by the mother, fear of litigation among caregivers and inappropriate organization of maternity care. ACOG recommends elective caesarean section after $39^{+0}$ weeks. $^{4}$

In our setup the exact schedule for caesarean section is not always possible due to large patient load, lot of unbooked, referral cases, ignorance and inability of women to comply with the instructions. There are limited studies done to determine the best gestational age of caesarean section for best fetal outcome in Indian population.
Hence study was conducted to find correlation between gestational age of elective caesarean section performed at 38 weeks, 39 weeks, 40 weeks and neonatal outcome and importance of gestational age of elective caesarean section for best neonatal outcome.

\section{Materials and Methods}

The study was conducted for a period of one and half years (Dec 2014 - May 2016) in Department of Obstetrics and Gynaecology, Dr. Baba Saheb Ambedkar Hospital in Delhi. The study was conducted on 750 singleton pregnant women who were admitted for elective caesarean section at different gestational ages. Patients with gestational age $<38$ weeks, medical disorders, placenta previa and placental abruption, multiple gestations, labour or attempted induction, spontaneous rupture of membranes, chorioamnionitis before delivery, Fetal distress, IUGR, polyhydromnios and oligohydromnios, history of myomectomy were excluded from the study.

All enrolled patients were divided into three groups. Group ' $A$ ' $(n=250)$ : Caesarean section was conducted at 38 weeks of gestation. Group 'B' $(n=250)$ Caesarean section was conducted at 39 weeks of gestation. Group ' $\mathrm{C}$ ' $(\mathrm{n}=250)$ : Caesarean section was conducted at 40 weeks of gestation.

Detailed history, general physical, systemic and obstetric examination was done. All routine blood investigations were done prior to surgery. After PAC (Pre anaesthetic checkup) patients were posted for elective caesarean section, any difficulties during caesarean section were noted, proper post operative 
care was taken. Neonates were attended by paediatrician at the time of delivery and initial essential care was taken, apgar score was noted, then transferred to nursery unit within 15 minutes. In nursery, newborns were kept under radiant warmer for about 1 hour. During this time a brief physical examination of neonate was performed to check for any deformities, complications, glucose level and body temperature. Follow up of neonates was done till discharge.

Neonatal outcomes recorded were: Birth weight, apgar score (at 1 and 5 minutes), respiratory complications, hypothermia (axillary temperature $<36.50 \mathrm{C}$ within 1 hour of life), hypoglycaemia $(<40$ $\mathrm{mg} / \mathrm{dl}$ within 1 hour of life), feeding difficulties, admission to neonatal intensive care unit (number of days of admission in NICU).

Statistical analysis was performed by using statistical software SPSS version 21.0. and Chi-Square test /Fisher's exact test, Anova/Kruskalwallis test were applied. P value $<0.05$ was considered significant.

\section{Observations and Results}

Out of 750 patients, majority of patients( $90.4 \%$ ) belonged to age group $21-30$ years, followed by $(9.33 \%)$ patients were $\leq 20$ years, only $(0.27 \%)$ patients were $>30$ years. Most number of the patients $(70.80 \%)$ were 2nd gravida. Majority of the cases (74.80\%) followed Hindu religion.

Total $40(5.33 \%)$ babies were <2500 grams, among them $12(4.80 \%)$ babies from group A, $14(5.60 \%)$ babies from group B, $14(5.60 \%)$ babies from group C.

Total $617(82.27 \%)$ babies were in the range of 2500 to 3000grams, among them $209(83.60 \%)$ babies from group A, $205(82 \%)$ babies from group B, 203(81\%) babies from group C.

Total $29(11.60 \%)$ of the babies were $<2500$ grams, among them $29(11.60 \%)$ babies from group A, 31 $(12.40 \%)$ babies from group B, $33(13.20 \%)$ babies from group $\mathrm{C}$.

The $\mathrm{p}$ value is 0.969 which is insignificant.

Table 1: Showing comparison of the birth weight among the three groups

\begin{tabular}{|c|c|c|c|c|c|c|c|c|c|}
\hline & \multicolumn{3}{|c|}{ Group } & \multirow{2}{*}{$\begin{array}{l}\text { Total } \\
\text { (750) }\end{array}$} & \multirow[t]{2}{*}{$P$ value } & \multirow[t]{2}{*}{ A vs B } & \multirow[t]{2}{*}{ A vs $\mathrm{C}$} & \multirow[t]{2}{*}{ B vs $\mathrm{C}$} \\
\hline & & $A(n=250)$ & $B(n=250)$ & $C(n=250)$ & & & & & \\
\hline \multirow{3}{*}{$\begin{array}{l}\text { Birth } \\
\text { Weight } \\
\text { (in grams) }\end{array}$} & 1) $<2500$ & $12(4.80 \%)$ & $14(5.60 \%)$ & $14(5.60 \%)$ & $40(5.33 \%)$ & \multirow[t]{3}{*}{0.969} & \multirow[t]{3}{*}{0.878} & \multirow[t]{3}{*}{0.779} & \multirow[t]{3}{*}{0.964} \\
\hline & $\begin{array}{c}\text { 2) } 2500- \\
3000\end{array}$ & $\begin{array}{c}209 \\
(83.60 \%)\end{array}$ & $205(82.00 \%)$ & $203(81.20 \%)$ & $617(82.27 \%)$ & & & & \\
\hline & 3) $>3000$ & $29(11.60 \%)$ & $31(12.40 \%)$ & $33(13.20 \%)$ & $93(12.40 \%)$ & & & & \\
\hline
\end{tabular}

Total $61(8.13 \%)$ babies apgar score at 1 min observed <7, $22(8.80 \%)$ babies from group A, 19 (7.60\%) from group B and 20 (8.00\%) from group C.

The difference between groups was not significant ( $\mathrm{p}$ value $=0.88$ ).

Table 2: Showing comparison of the apgar score at $1 \mathrm{~min}$ among the three groups

\begin{tabular}{|c|c|c|c|c|c|c|c|c|c|}
\hline & \multicolumn{3}{|c|}{ Group } & \multirow{2}{*}{$\begin{array}{l}\text { Total } \\
\text { (750) }\end{array}$} & \multirow{2}{*}{$P$ value } & \multirow{2}{*}{ A vs B } & \multirow{2}{*}{ A vs $\mathrm{C}$} & \multirow{2}{*}{ B vs C } \\
\hline & & $\mathbf{A}(\mathbf{n}=\mathbf{2 5 0})$ & $\mathrm{B}(\mathrm{n}=\mathbf{2 5 0})$ & $\mathrm{C}(\mathrm{n}=250)$ & & & & & \\
\hline \multirow{2}{*}{$\begin{array}{l}\text { Apgar } \\
\text { Score At } 1 \\
\text { Min }\end{array}$} & $\geq 7$ & $228(91.20 \%)$ & $231(92.40 \%)$ & $230(92.00 \%)$ & $689(91.87 \%)$ & \multirow[b]{2}{*}{0.883} & \multirow[b]{2}{*}{0.625} & \multirow[b]{2}{*}{0.747} & \multirow[b]{2}{*}{0.868} \\
\hline & $<7$ & $22(8.80 \%)$ & $19(7.60 \%)$ & $20(8.00 \%)$ & $61(8.13 \%)$ & & & & \\
\hline
\end{tabular}

Total 8 (1.07\%) babies had apgar score $<7$ at $5 \mathrm{~min}, 4(1.60 \%)$ from group A, 2(0.80\%) from group B, 2 $(0.80 \%)$ from group C. Difference between groups was statistically not significant $(\mathrm{p}=0.603)$.

Total $25(3.33 \%)$ babies developed respiratory complications, 10 (4.00\%) babies in group A, 8(3.20\%) babies, 7 $(2.80 \%)$ in group $\mathrm{C}$. The difference between three groups was statistically not significant ( $\mathrm{p}$ value $=0.749$ ).

Table 3: Showing comparison of the respiratory complications among the three groups

\begin{tabular}{|c|c|c|c|c|c|c|c|c|c|}
\hline & \multirow{2}{*}{\multicolumn{3}{|c|}{ Group }} & \multirow{3}{*}{$\begin{array}{l}\text { Total } \\
\text { (750) }\end{array}$} & \multirow{3}{*}{$P$ value } & \multirow{3}{*}{ A vs B } & \multirow{3}{*}{ A vs $C$} & \multirow{3}{*}{ B vs $\mathrm{C}$} \\
\hline & & & & & & & & & \\
\hline & & $\mathbf{A}(\mathbf{n}=\mathbf{2 5 0})$ & B $(n=250)$ & $C(n=250)$ & & & & & \\
\hline \multirow{2}{*}{$\begin{array}{l}\text { Respiratory } \\
\text { Complications }\end{array}$} & Yes & $10(4.00 \%)$ & $8(3.20 \%)$ & $7(2.80 \%)$ & $25(3.33 \%)$ & \multirow{2}{*}{0.749} & \multirow{2}{*}{0.631} & \multirow{2}{*}{0.459} & \multirow{2}{*}{0.793} \\
\hline & No & $240(96.00 \%)$ & $242(96.80 \%)$ & $243(97.20 \%)$ & $725(96.67 \%)$ & & & & \\
\hline
\end{tabular}

Hypothermia seen in totally $27 / 750$ cases, $13 / 250$ (5.20\%) in group A, $9 / 250(3.6 \%)$ in group B, $5 / 250(2 \%)$ in group $\mathrm{C}$, The difference between three groups was statistically not significant ( $\mathrm{p}$ value $=0.15$ ). 
Table 4: Showing comparison of the hypothermia among the three groups

\begin{tabular}{|c|c|c|c|c|c|c|c|c|c|}
\hline & \multicolumn{3}{|l|}{ Group } & \multirow{2}{*}{$\begin{array}{l}\text { Total } \\
(750)\end{array}$} & \multirow{2}{*}{$P$ value } & \multirow{2}{*}{ A vs B } & \multirow{2}{*}{ A vs $\mathrm{C}$} & \multirow{2}{*}{ B vs C } \\
\hline & & $A(n=250)$ & B $(n=250)$ & $C(n=250)$ & & & & & \\
\hline \multirow{2}{*}{ Hypothermia } & Yes & $13(5.20 \%)$ & $9(3.60 \%)$ & $5(2.00 \%)$ & $27(3.60 \%)$ & \multirow{2}{*}{0.15} & \multirow{2}{*}{0.3} & \multirow{2}{*}{0.055} & \multirow{2}{*}{0.278} \\
\hline & No & $237(94.80 \%)$ & $241(96.40 \%)$ & $245(98.00 \%)$ & $723(96.40 \%)$ & & & & \\
\hline
\end{tabular}

Only 1 case of hypoglycaemia observed in group A, which is statistically insignificant ( $p$ value $=0.367$ ). The difference between three groups was not significant ( $\mathrm{p}$ value $=0.603$ ).

Totally only 3(0.40) babies developed sepsis, $2(0.80 \%)$ babies in group A, $1(0.40 \%)$ in group C, none of the babies developed sepsis in group B. The difference between three groups was statistically not significant $(p$ value $=0.366$ ).

Total 49/750 (6.53\%) babies were admitted in NICU, 19/250(7.60\%) babies from group A, 15/250(6.00\%) from group B, $15 / 250(6.00 \%)$ by group C. The difference between three groups was statistically not significant $(p$ value $=0.705$ ).

Table 5: Showing comparison of the NICU admissions among the three groups

\begin{tabular}{|c|c|c|c|c|c|c|c|c|c|}
\hline & \multicolumn{3}{|c|}{ Group } & \multirow[b]{2}{*}{$\begin{array}{l}\text { Total } \\
(\mathbf{7 5 0})\end{array}$} & \multirow[b]{2}{*}{ P value } & \multirow[b]{2}{*}{ A vs B } & \multirow[b]{2}{*}{ A vs C } & \multirow[b]{2}{*}{ B vs C } \\
\hline & & $\begin{array}{c}\mathbf{A} \\
(\mathrm{n}=\mathbf{2 5 0})\end{array}$ & $\begin{array}{c}B \\
(n=250)\end{array}$ & $\begin{array}{c}\mathbf{C} \\
(n=250)\end{array}$ & & & & & \\
\hline \multirow{2}{*}{$\begin{array}{l}\text { NICU } \\
\text { Admission }\end{array}$} & Yes & $19(7.60 \%)$ & $15(6.00 \%)$ & $15(6.00 \%)$ & $49(6.53 \%)$ & \multirow{2}{*}{0.705} & \multirow{2}{*}{0.477} & \multirow{2}{*}{0.477} & \multirow{2}{*}{1.000} \\
\hline & No & $231(92.40 \%)$ & $235(94.00 \%)$ & $235(94.00 \%)$ & $701(93.47 \%)$ & & & & \\
\hline
\end{tabular}

Total 33/250 (4.40\%) babies were stayed in hospital for $\geq 5$ days, 13/250 (5.20\%) babies of group A, 10/250 $(4.00 \%)$ babies of group B, 10/250 (4.00\%) babies of group C. The difference between three groups was statistically not significant ( $\mathrm{p}$ value $=0.603$ ).

\section{Discussion}

The mean age of three study groups in our study was between 21-30 years with the minimum age of 18 years and maximum age of 31 years. The $p$ value is 0.230 which is insignificant suggesting that distribution of population according to age was similar for each of the groups.

Apgar score $<7$ at 1 min observed in total $61 / 750$ $(8.13 \%)$ of the babies. At 38,39 , and 40 weeks babies with low apgar scores were 22(8.8\%), 19 (7.6\%) and 20 $(8.0 \%)$ respectively $(\mathrm{p}=0.88)$. Most of these babies improved in apgar score $>7$ at $5 \mathrm{~min} .8(1.07 \%)$ babies were low in apgar score at $5 \mathrm{~min}$, among these 38 weeks babies are 4, 39 weeks babies are 2 and 40 weeks babies are $2(\mathrm{p}=0.603)$. These babies were shifted to NICU for close monitoring and further interventions according to need. These results are comparable to study done by $\mathrm{J}$ Glavind, et $\mathrm{al}^{5}$ they observed apgar score $<7$ of 38 and 39 weeks neonates at 1 min was $3.1 \%$ and $3.8 \%$ respectively. And apgar score $<7$ of 38 and 39 weeks neonates at $5 \mathrm{~min}$ was $1 \%$ and $1.9 \%$ respectively, which explains no difference in apgar score at $1 \mathrm{~min}$ and $5 \mathrm{~min}$ in 38 and 39 weeks neonates.

Feeding difficulties was observed in total 37 (4.93\%) babies. Out of which $14(5.60 \%)$ babies were in 38 weeks, $13(5.20 \%)$ babies in 39 weeks, 10(4.0\%) in 40 weeks $(\mathrm{p}=0.691)$. Among 3 groups, one baby of 38 weeks developed hypoglycaemia. In a study done by Eman A. Hussein Aly ${ }^{6}$ observed that 2 (2.19\%) babies delivered at 38 weeks and $1(2.04 \%)$ baby delivered at 39 weeks developed hypoglycaemia. In our study also

there is no significant difference in development of hypoglycaemia among three groups.

Hypothermia developed in total of $27(3.6 \%)$ babies. In 38, 39 and 40 weeks the rates are $5.2 \%, 3.6 \%$ and $2 \%$ respectively $(\mathrm{p}=0.158)$. No studies were done previously to find difference in hypothermia of babies delivered by elective caesarean section at 38,39 and 40 weeks.

The respiratory complications(respiratory distress syndrome, transient tachypnea of the newborn) developed in $25(3.33 \%)$ babies, out of these $10(4 \%)$ babies were 38 weeks, 8 (3.2\%) babies were 39 weeks and $7(2.8 \%)$ babies were 40 weeks developed these complications $(\mathrm{p}=0.749)$. Transient tachypnea of the newborn is the most common respiratory problem in neonates delivered by caesarean section rather than respiratory distress syndrome. All these babies were admitted in NICU only 2 babies 1 of 38 weeks and 1 of 40 weeks needed mechanical ventilation, this 38 weeks baby developed sepsis but recovered completely. Overall $3(0.40 \%)$ babies developed sepsis 2 babies of 38 weeks and 1 baby of 40 weeks, none in 39 weeks( $\mathrm{p}=0.366$ ). In a study done by Dalva Lucia et al, ${ }^{7}$ observed incidence of neonatal sepsis in 38 weeks was $2 / 224,39$ weeks was $1 / 221$ and 40 weeks was $0 / 102$.

Rate of NICU admission was $6.53 \%$ (49/750) in this study. At 38, 39 and 40 weeks, the percentage of NICU admission was $7.60 \%$ (19/250), 6\% (15/250) and $6 \%(15 / 250)$ respectively. However using the Chi square test $(\mathrm{p}=0.705)$ and there was no significant relation between weeks of gestation and the rate of NICU admission. In a study done by Glavind $\mathrm{J}$ et $\mathrm{al}^{5}$ observed rates of NICU admission for $>2$ days after 
elective caesarean delivery were $6 \%, 6.1 \%$ for 38 and 39 weeks of gestation respectively which were comparable to our results.

Overall 33(4.4\%) of babies stayed in hospital $\geq 5$ days. In 38, 39 and 40 weeks, babies stayed in hospital $\geq 5$ days were $13(5.2 \%), 10(4 \%)$ and $10(4 \%)$ respectively $(\mathrm{p}=0.752)$. These results are supported by the study done by Tita $\mathrm{AT}$ and Landon $\mathrm{MB}^{8}$ who analyzed the timing of elective repeat caesarean delivery at term and neonatal outcomes. They observed percentage of the newborns admitted in hospital $>5$ days $5.7 \%, 3.6 \%$ and $4.1 \%$ at 38,39 and 40 weeks respectively. No death observed in three groups during hospital stay.

\section{Conclusion}

Neonatal outcomes are similar in elective caesarean sections done at 38,39 and 40 weeks of gestation. So elective caesarean section can be done in between 38 to 40 weeks depending upon the resources available in a as the neonatal outcomes at 38 weeks are similar to 39 and 40 weeks. Large sample size could have been analyzed. Long term complications of the newborns could have been analysed.

\section{Acknowledgment}

The authors would like to thank all the faculty members of Department of Obstetrics and Gynaecology, Dr. Baba Saheb Ambedkar Medical College \& Hospital for their support in reporting these observations.

Conflict of Interest: All authors declare that they have no conflict of interest.

\section{References}

1. Bhasin, SK et al. A high prevalence of caesarean section rate in East Delhi. Indian J Community Med 2007;32:222-4.

2. Williams obstetrics textbook; 24 th edition. 30;587.

3. Williams obstetrics textbook; 23rd edition. 25;544.

4. American College of Obstetricians and Gynecologists (ACOG) Committee on Practice Bulletins. ACOG Practice Bulletin. No.107. Induction of Labor. Obstetrics \& Gynecology,2009114:386-97.

5. Glavind J, Kindberg S, Uldbjerg N, Khalil M, Møller A: Timing of Elective caesarean section at 38 weeks versus 39 weeks: neonatal and maternal outcomes in a randomised controlled trial. BJOG 2013;120:1123-1132.

6. Eman A. Hussein ALY, M.D: Elective Caesarean Deliveries at Term and Evaluation of the Neonatal Outcomes; Med. J. Cairo Univ., Vol. 81, No. 1,June: 491495,2013.

7. Carrilho Dalva Lucia Cotrim Pereira, Veiga Ana Paula Rocha, Bernardo Wanderley Marques, Gonzales Beatriz Alvarenga. Is there any increase in newborn morbidity in elective C-sections performed before the 39th week of pregnancy?. Rev. Assoc. Med. Bras. 2015 Feb; 61(1):2222.

8. Tita AT, Landon MB; Timing of elective repeat cesarean delivery at term and neonatal outcomes: N Engl J Med. 2009 Jan 8;360(2):111-20. 